\title{
A report on the recruitments of Alopias Pelagicus and Alopias Superciliosus in the Andaman Sea
}

\begin{abstract}
The reproductive biology of commercially important Alopias superciliosus and Alopias pelagicus bears great importance. The present study reports for the gravid females from the Andaman Sea the first time. Parturient sharks have been rarely observed in the wild, with very sparse data regarding the reproductive strategies of most oceanic species from Andaman and Nicobar waters. During this study, from the uterine cavity of Alopias superciliosus and Alopias pelagicus, two pups each were recovered alive. Total Length (TL) of gravid Alopias superciliosus and Alopias pelagicus measured to be $353 \mathrm{~cm}$ and $286 \mathrm{~cm}$, weighing $145 \mathrm{~kg}$ and $65 \mathrm{~kg}$ respectively. Both the gravid sharks bore male and female embryos in right and left uterus. The embryos found in Alopias superciliosus measured $140 \mathrm{~cm}$ (male) and $143 \mathrm{~cm}$ (female) in TL, whereas the embryos found in Alopias pelagicus measured $120 \mathrm{~cm}$ (male) and $122 \mathrm{~cm}$ (female). The present study estimated the gestation period for 9 months in Alopias pelagicus as well as in Alopias superciliosus. Though further investigation are required to confirm various reproductive informations such as delayed or late maturity, synchronous reproductive cycle and low biological productivity however this study confirms only two embryos per uterus.
\end{abstract}

Keywords: Gravid, Litter, Embryos, Viviparous, Oophagus, Alopias superciliosus, Alopias pelagicus
Volume 4 Issue 6 - 2016

\author{
Pratyush Das, Manas Kumar Sinha, Ajay \\ Kumar Bhargava, Puran Singh, Kanhu Charan \\ Sahu, Kiran Shankar Mali \\ Fishery Survey of India, India
}

\begin{abstract}
Correspondence: Pratyush Das, Fishery Survey of India, Phoenix Bay, Port Blair,Andaman and Nicobar Islands, Tel 91 9679534088,Email pratyush84@gmail.com
\end{abstract}

Received: October 31, 2016 | Published: December 02, 2016

\section{Introduction}

The big eye thresher shark (Alopias superciliosus) and the pelagic thresher (Alopias pelagicus) belonging to the family of Alopiidae are the deep dwelling shark species that are caught frequently by long liners in the Andaman Sea. Both the sharks are easily characterized by elongated upper lobe of the caudal fin inhabitating from temperate to sub-tropical oceans worldwide or are cosmopolitan in nature. Catch records indicate that the big eye thresher followed by pelagic thresher sharks typically inhabits deeper waters than the common thresher shark Alopias vulpinus. In the Andaman Sea, all the three varieties of Alopias species have been recorded. ${ }^{1}$ The reproductive biology of commercially important Alopias superciliosus bears great importance and studies regarding the reproductive biology were made from the Eastern and Western Atlantic ${ }^{2-6}$ in Taiwan ${ }^{7}$ and from the Arabian Sea. ${ }^{8}$ Reproductive biology of Alopias pelagicus was also studied from Philippines ${ }^{9}$ and from the Equatorial Pacific. ${ }^{10}$ Both the species are ovoviviparous and Oophagus ${ }^{11}$ in the wild, due to the eggs capsules and fragment of shell found in the guts of embryos and usually produces two pups per litter (occasionally four pups per litter) ${ }^{12}$ established that the Alopias pelagicus has two embryos per litter and mature at a moderate age, and if a female gives birth once a year they only produce about 40 embryos per generation. Based on the spawning per recruit studies,$^{13}$ suggested that in Taiwan waters, the stock were slightly overexploited and this gets a conclusion that Alopias pelagicus is extremely vulnerable to overexploitation. The species needs immediate attention for its management ${ }^{12,14} \&^{4}$ documented a single embryo in each uterus at parturition in each case of Carcharias taurus captured worldwide. Fishery biology including age and growth and reproductive biology of the Alopias superciliosus has been reported..$^{15,16}$ Fishery biology of the pelagic thresher shark, Alopias pelagicus have been described respectively. ${ }^{12}$ documented that Alopias pelagicus caught from North Eastern Taiwan breeds throughout the year. The reproductive cycle of sharks can be defined by how often a species breeds which consists of two periods.
The first period is the vitellogenesis period, when nutrients are stored in the liver and are transferred to the developing oocytes in the ovaries, and then the oocytes accumulate yolk which grows rapidly. The second period is the gestation period, or the time of embryonic development starting from fertilization to birth. Vitellogenesis period and gestation period can run concurrently or consecutively, and the duration of each period may vary. The duration of these two periods depend on how effectively the mother shark can sequester energy from the surrounding environment and how the mother shark transfers it to the developing oocytes or embryos, and on the mode of embryonic nutrition. Together, these two periods i.e. vitellogenesis and gestation, determines the length of the reproductive cycle. In a given shark population, the females can be reproductively synchronous or asynchronous. Synchronous females remains in the same stage of the reproductive cycle, while in a population of asynchronous females, all the sharks may be at different stages of the reproductive cycle. Generally, the females are synchronous in the species that inhabit in temperate waters, where birth must occur at the most propitious time for the young to survive, generally in spring or summer when temperatures are well within the thermal tolerances of the species and when prey or food are abundant. Females are often reproductively asynchronous in the shark species which dwell in tropical waters, which experiences a stable environmental condition with availability of abundant food throughout the year that permits reproduction and birth to occur.

The size at birth for has been reported between $60 \mathrm{~cm}$ TL to 140 cm TL by $(100-103 \mathrm{~cm}),{ }^{14}(64 \mathrm{~cm}),{ }^{17}(68 \mathrm{~cm}),{ }^{18}(64-106 \mathrm{~cm}),{ }^{4}(105$ $\mathrm{cm}),{ }^{19}(100-103 \mathrm{~cm}),{ }^{20}(100),{ }^{6}(135-140 \mathrm{~cm})^{15}$ and $(130-158 \mathrm{~cm}) .{ }^{8}$ No mating signs in gravid sharks were observed. ${ }^{21}$ This variation in size at birth may be due to environmental factors. ${ }^{6}$

${ }^{1}$ Reported the spatio-temporal distribution, abundance and biodiversity of Sharks in Andaman and Nicobar waters. They reported 14 species of sharks in the oceanic waters of Andaman Sea by long lining survey out of which 7 species are frequently occurring species. 
They are Alopias pelagicus, Alopias supercilliosus, Alopias vulpinus, Carcharhinus limbatus, C. albimarginatus, C. sorrahand G. cuvier. However till date no information regarding the nursery area, gestation period or pupping season of these sharks in the Andaman Sea is reported by any researcher. During this study an maiden attempt was made to report the morphometry, embryology and size at birth of these two species of Alopias from Andaman waters.

\section{Materials and methods}

\section{Study area}

The pristine Andaman and Nicobar Islands consists of a group of 572 Islands and located at an approximate distance of $1200 \mathrm{Km}$ from Indian continent (Figure 1), off the East Coast of India in the Bay of Bengal (Lat. $6^{\circ} 45^{\prime}-13^{\circ} 45^{\prime} \mathrm{N}$ and Long $92^{\circ} 15^{\prime}-94^{\circ} 00^{\prime} \mathrm{E}$ ) forming India's southeast border. The group of Islands are surrounded by Andaman Sea which is considered to be in the cradle of Bay of Bengal. These Islands have proximity to some South East Asian countries like Malaysia, Myanmar, Thailand, Singapore and Indonesia. Average area of Andaman sea is about $6,00,000 \mathrm{Km} 2$ with a coastal stretch of $1912 \mathrm{Km}$ and its average depth was estimated to be 1, 096 meters. It is a maritime regime containing internal solitary waves of extraordinary amplitude (>60 m), wave length $(6-15 \mathrm{Km})$, and speed $(>2.0 \mathrm{~m} / \mathrm{s}) .^{22}$ In the Southern part, Salinity ranges from 31.5 to 32.5 PSU and fluctuations are seen in the Northern part (20 to 25 PSU) due to inflow of freshwater. The Islands experience tropical climate i.e. South West (April-September) and North East (October-December) for which monsoons are frequent and average rainfall is between 3,000 to $3,500 \mathrm{~mm} .{ }^{23}$ Andaman Sea is also the genesis ground of many cyclonic storms (e.g. Phailin, Hudhud, SIDR, Lehar, etc.) which cross East coast of India and is also the basin for generation of tsunami in the Indian Ocean. Water pollution in Andaman Sea experiences a lot of variance. Some parts have excellent water medium and some have poor quality. Higher coastal water quality index was perceived in open sea. ${ }^{24}$ From commercial point of view, Marine fisheries of these Islands tender high demand in export. Snappers (Lujanidae), Groupers (Serranidae), Emperors (Lethrinidae), Jacks (Carangidae), Indo-pacific king mackerel (Scomberomorus guttatus), Indian Mackerel (Rastrelliger kanagurta), Sardines (Clupidae), Anchovies (Engraulidae), Lobsters (Nephropidae), various species of Crabs, are the important constituents of landings. ${ }^{39} \mathrm{~A}$ big share of Oceanic Tuna like Thunnus albacares, Thunnus obesus and Katsuwonus pelamis is obtained from the EEZ of these Islands. ${ }^{38}$ Non-target species such as Sharks, Marlin spp., Swordfish, Barracuda spp., makes up $50 \%$ of by-catch. ${ }^{25}$

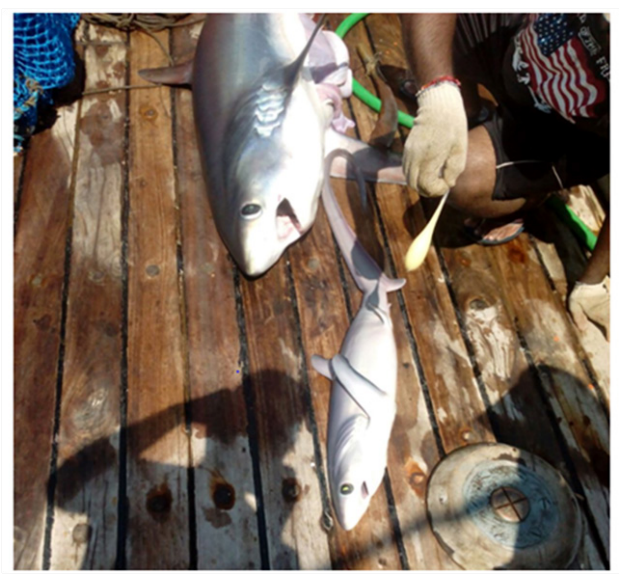

Figure I Alopias superciliosus.

\section{Methodology}

Fishery Survey of India (FSI), Port Blair, a sub-ordinate office under the administrative control of Department of Animal Husbandry, Dairying and Fisheries, Ministry of Agriculture and Farmers Welfare, Government of India, New Delhi carried out extensive exploratory survey on Oceanic Tuna and allied resources by operating Multifilament long line gear (Five hooks per basket) in the Andaman Sea by deploying a survey ship namely "MFV Blue Marlin" attached to the Zonal Base of FSI, Port Blair during April 2016. Two gravid sharks viz. Alopias pelagicus and one Alopias superciliosus were caught in the coordinates of Lat. $11^{\circ} 24.2^{\prime} \mathrm{N}$ and Long. $92^{\circ} 47.6^{\prime} \mathrm{E}$ and Lat. $11^{\circ} 29.6^{\prime} \mathrm{N}$ and Long. $93^{\circ} 22.6^{\prime} \mathrm{E}$ i.e. from the Eastern part of Andaman Sea. The morphometric measurements of the two shark species were recorded in centimetres by using the measuring tape and the weight of the species were recorded in kilograms by using spring balance. All the terminology related to this study along with morphometric and meristic characters for the present study were followed from. ${ }^{14,19,26}$ For the biological studies, the fishes caught were dissected out onboard and the gut was cut open to find the contents by physical examination.

\section{Results and discussion}

The present study reports for the first time the gravid females from the Andaman Sea (Figure 1-4). Parturient sharks have been rarely observed in the wild, with very sparse data regarding the reproductive strategies of most oceanic species. From the uterine cavity of Alopias superciliosus and Alopias pelagicus, two pups each were recovered alive. Total Length (TL) of gravid Alopias superciliosus and Alopias pelagicus measured to be $353 \mathrm{~cm}$ and $286 \mathrm{~cm}$, weighing $145 \mathrm{~kg}$ and $65 \mathrm{~kg}$ respectively. Both the gravid sharks bore male and female embryos in right and left uterus. The embryos found in Alopias superciliosus measured $140 \mathrm{~cm}$ (male) and $143 \mathrm{~cm}$ (female) in TL, whereas the embryos found in Alopias pelagicus measured 120 $\mathrm{cm}$ (male) and $122 \mathrm{~cm}$ (female) in TL with non-calcified claspers respectively. ${ }^{10}$ observed pelagic thresher sharks that had a pre-caudal length of fewer than $124 \mathrm{~cm}$ have non-calcified claspers. The embryos of Alopias superciliosus weighed $05 \mathrm{~kg}$ (male) and $05 \mathrm{~kg}$ (female), whereas the embryos of Alopias pelagicus weighed $06 \mathrm{~kg}$ (male) and $07 \mathrm{~kg}$ (female). The embryos consume vitellus from the egg and later feed on unfertilized eggs produced by the mother that are covered by a capsule. ${ }^{10}$ The capsules varied in number in different proportion in each uterus. Gravid Alopias superciliosus contained nearly 45 yolk filled egg capsule measuring $56.9 \mathrm{~mm}$ to $277.01 \mathrm{~mm}$ in length, 14.03 to $22.56 \mathrm{~mm}$ in width, weighing $1.1 \mathrm{~g}$ to $16.25 \mathrm{~g}$. Embryos were large in appearance to be termed fetuses and capsules were comparatively less in number. The developing embryos have Oophagus, feeding on unfertilized eggs produced by the mother. The ovary of Alopias superciliosus weighed about $238 \mathrm{~g}$ containing 730 ova with $1.1 \mathrm{~mm}$ to $4.5 \mathrm{~mm}$ in diameter and the horny infertile eggs contained therein were deposited in each oviduct and the embryo consumes these as development proceeds ${ }^{18,27}$ and in-case of Alopias pelagicus, the ovary weighed about $232 \mathrm{~g}$ containing 698 ova with similar results as compared with the former. This study observed continuous vitellogenesis in the recorded gravid females, and the size ovary did not decrease during pregnancy even (the oocytes were even larger in gravid females), suggesting an annual cycle with concurrent vitellogenesis and gestation, as described by ${ }^{28}$ for $A$. pelagicus and $A$. superciliosus. The embryos recovered were an exact replica of the adult sharks and consumed whole unfertilized eggs. All females under $140 \mathrm{~cm}$ PCL were immature due to the reduced development of reproductive structures, mainly the ovary and the oviduct glands. 
From this size the development increases and the oocytes present vitellogenic activity, the glands develop significantly and the uterus walls becomes thicker. Glands widen and may have an external reddish colour. Gravid females with embryos, are easily characterized by having larger ovaries that could reach $40 \mathrm{~cm}$ in length and the oocytes are completely full of vitellus. ${ }^{10}$

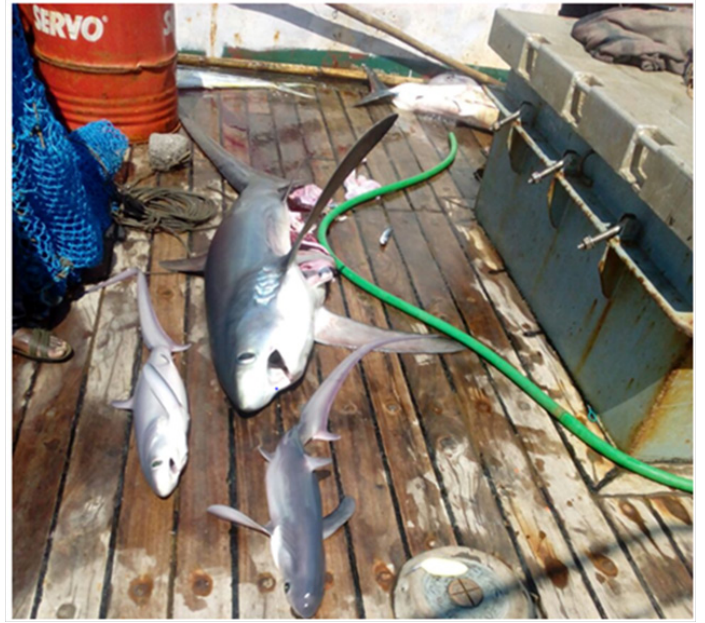

Figure 2 Gravid sharks and Juveniles of Alopias superciliosus caught through longlining by MFV Blue Marlin.

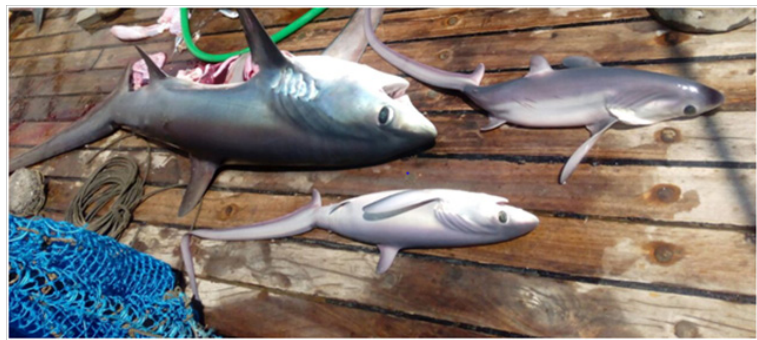

Figure 3 Gravid sharks and Juveniles of Alopias pelagicus.

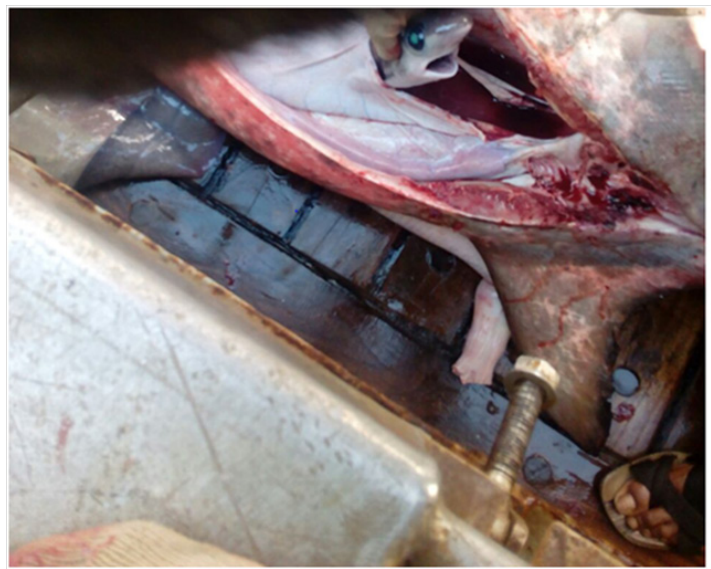

Figure 4 Gravid sharks and Juveniles of Alopias pelagicus.

For Alopias superciliosus, the maturity was reported between 279$300 \mathrm{~cm}$ TL and 332-341 cm TL for males and females, ${ }^{3,15}$ but in case of Alopias vulpinus, ${ }^{29}$ estimated a median size at maturity for males to be $188 \mathrm{~cm}$ in FL (fork length) and $216 \mathrm{~cm}$ FL for females. This study finds out size of $353 \mathrm{~cm}$ TL in case of Alopias superciliosus. The sizes at maturity under $100 \mathrm{~cm}$, reported by Bigelow et al. \& Cadenat $^{17,18}$ were likely to be only underestimations, which might have resulted from smaller gravid female. As per the observations in the present study, the embryos had reached the sizes and the survival opportunities increased in neonates of larger sizes and with abundant nutritive supplements. Similar reports were also made by ${ }^{30,31}$ stated that the only benefit in having large neonates is not else than enhanced prey capturing and predator-escaping abilities, thus by improving their effective survival chances after parturition. The embryonic nutrition and growth of Alopias superciliosus have been well studied and reported by several authors like. ${ }^{19,30}{ }^{6}$ However, only ${ }^{30}$ gave a detailed description of embryonic development in Bigeye Thresher Alopias superciliosus.

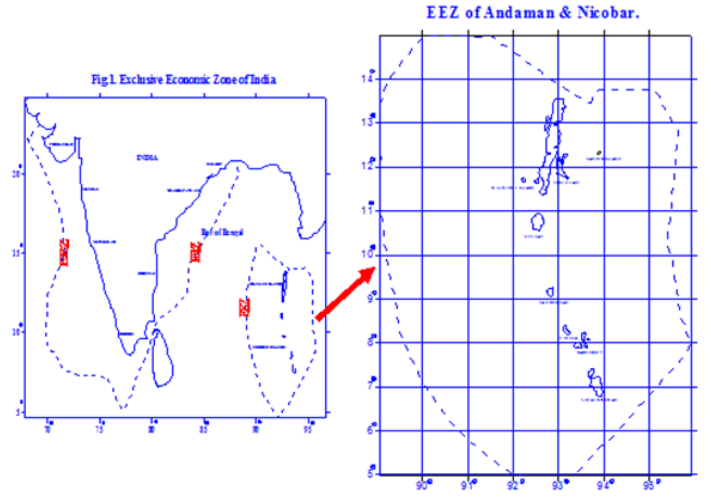

Figure 5 Study area (Andaman Sea)

The present study estimated the gestation period for 9 months in Alopias pelagicus as well as in Alopias superciliosus. Further it is important to mention that the embryos are quite synchronous and present themselves in an annual pattern, which could not be established by $^{12}$ for the species of Alopias pelagicus in Taiwan waters, because they found females in various gravid stages throughout the year. During the study it was found that the Alopias superciliosus and Alopias pelagicus embryos were covered with a smooth epithelium covering the well-developed dermal denticles of the second epithelial and this layer probably protects the highly vascularised uterine lining from the sharp denticles of large active embryo and may also helps in allowing the embryo to make a easy exit during parturition. The smooth outer epithelial layer has not been described for other Alopid embryos which may be a major character only found in Alopias superciliosus..$^{27,32,33}$ The embryo of Alopias superciliosus examined had well developed spinous denticles, therefore apparently necessitating the presence of a smooth and protective outer epithelium. The embryo was considered to be near term as no encapsulated ova were found in the oviduct, which indicates that the ovulation was declining or has ceased. The reduced size of parental ovary indicates that this embryo had just passed through the period of maximum oophagy and was nearing parturition. The above facts may indicate that in A. superciliosus, the embryos were fully nourished by the ova from the maternal fish and so are the oophagous (egg eaters) by nature. There were no connection or structures like placenta between them intra uterine wall of mother and the embryo. They are a placental viviparous species. When compared to other oophagous Lamnoid sharks, $A$. superciliosus embryos do not acquire large distended yolky stomachs. It is evident in the present study that $A$. superciliosus embryos are externally well formed and partly pigmented when they are only about $60 \mathrm{~cm}$. The fully formed external appearance of embryos has caused researchers to therefore overestimate how close embryos are close to birth and to underestimate the birth size. It is only after examining a decent number of gravid females the confirmation can be made whether it is term fetus or early one. Similar reports were also 
reported. ${ }^{34,35}$ Reported that most large females throughout the year contained embryos and if this is the reproductive pattern similar to that of the $A$. vulpinus ${ }^{27,36}$ then mating occurs throughout the year. This study also in agreement with the above statement. In Andaman waters, the study on reproductive biology of Alopias pelagicus and Alopias superciliosus is little known and further investigation are required to confirm various reproductive informations such as delayed or late maturity, synchronous reproductive cycle and low biological productivity, having only two embryos per uterus. However, ${ }^{1}$ in their study also reported 2 to 4 embryos per uterus. But in this study only two embryos could be recovered.

\section{Conclusion}

As per the recent estimate of FSI, the sharks has got a potential of about 11, 200 tonnes per annum from this emerald island waters whereas the landing is less than $6 \%$ on an average. ${ }^{1}$ Therefore the scope for exploitation is bright and it needs resource specific gear for yielding higher catch rates as also suggested. ${ }^{37}$ However, a more detailed study on the reproductive biology, food and feeding habits, and Growth parameters of all the three species of Alopidae is the need of the hour so as to understand the fishery effectively. Unless the detailed biology of the species is known then it will be hard to conclude the nature of the fishery. Being the first report it throws light on the subject of importance.

\section{Acknowledgements}

The authors are thankful to Shri Premchand, Director General, Fishery Survey of India, Ministry of Agriculture and Farmers Welfare, Government of India for his consistent support and encouragement. The authors are also thankful to the Skipper and vessel crew of MFV Blue Marlin, who put their consistent effort for acquiring the dataset. Support from the Ministry of Agriculture and Farmers Welfare, New Delhi is highly acknowledged.

\section{Conflicts of interest}

None.

\section{References}

1. Sinha MK, Paul Pandian P, Pattnayak S K Kar AB. Spatio- temporal distribution, abundance and diversity of oceanic sharks occurring in Andaman \& Nicobar watersin recent trends in biodiversity of Andaman \& Nicobar Islands in Ramakrishna \& Sivaperuman C (Eds.), Recent Trends in Biodiversity of Andaman and Nicobar Island. Zoological Survey of India, Kolkata. 2010;pp.373-385.

2. Stillwell C, Casey JG. Observations on the bigeye thresher shark, Alopias superciliosus, in the western North Atlantic Fish Bull. 1976;74:221-225.

3. Gruber SH, Compagno LJV. Taxonomic status and biology of the bigeye thresher, Alopias superciliosus. US Fish Bull. 1981;79:617-640.

4. Gilmore Grant R. Observations on the Embryos of the Longfin Mako, Isurus paucus, and the Bigeye Thresher, Alopias superciliosus. Copeia. $1983 ; 2: 375-382$.

5. Gilmore GR. Reproductive biology of lamnoid sharks. Environmental Biology of Fishes. 1993;38:95-114.

6. Moreno JA, Moron J. Reproductive biology of the bigeye thresher shark, Alopias superciliosus (Lowe, 1839) Aust J Mar Freshwater Res. 1992;43(1):77-86.

7. Nakamura, H. On the two species of the thresher shark from Formosan waters. Mem Fac Sci Agri, Taihoku Imperial University. 1935;14:1-6.
8. Benjamin D, Madhusoodana Kurup B, Harikrishnan M, et al. First Report on Recruits of Bigeye Thresher Shark Alopias Superciliosus(Laminiformes: Alopidae) with Largest Birth Size from Indian Waters , IJSRSET. Volume. 2015;1(4):216-220.

9. Oliver SP, Bicskos Kaszo AE. A pelagic thresher shark (Alopias pelagicus) gives birth at a cleaning station in the Philippines, Coral Reefs. 2015;34(1):17.

10. Romero caicedo AF, Galva'n-magana F, Marti'nez-ortiz J. Reproduction of the pelagic thresher shark Alopias pelagicus in the equatorial Pacific, Journal of the Marine Biological Association of the United Kingdom. 2014;94(7):1501-1507.

11. Otake T, Mizue K. Direct evidence for oophagy in thresher shark, Alopias pelagicus. Jap J Ichthyol. 1981;28(2):73-79.

12. Liu Kwang-Ming, Liu, Che-Tsung Chen, et al. Age, Growth, and Reproduction of the Pelagic Thresher Shark, Alopias pelagicus in the Northwestern Pacific, Copeia. 1999;1999(1):68-74.

13. Liu Kwang-Ming, Yu-Ting Chang, I-Hsun Ni, et al. Spawning per recruit analysis of the pelagic thresher shark, Alopias pelagicus, in the eastern Taiwan waters. Fisheries Research. 2006;82(1-3):56-64.

14. Bass A, Aubrey JD, Kistnasamy N. Sharks of the east coast of southern Africa. IV. The families Odontaspididae, Scapanorhynchidae, Isuridae, Cetorhinidae, Alopiidae, Orectolobidae and Rhiniodontidae. Oceanogr Res Inst (Durban) Invest Rep. 1975;39:1-102.

15. Chen CT, Liu KM, Chang YC. Reproductive biology of the bigeye thresher shark, Alopias superciliosus (Lowe, 1839) (Chondrichthyes: Alopiidae), in the northwestern Pacific. Ichthyological Research. 1997;44(2-3):227-235.

16. Liu KM, Chiang PJ, Chen CT. Age and growth estimates of the bigeye thresher shark, Alopias superciliosus, in northeastern Taiwan waters Fishery Bulletin. 1998;96:482-491.

17. Bigelow HB, Schroeder WC. Sharks In Tee-Van J, Breder CM, Hildebrand SF, et al. (eds.) Fishes of the Western North Atlantic. Part one. Lancelets, cyclostomes, sharks. Sears Foundation for Marine Research, Yale University, New Haven pp.1948;576.

18. Cadenat J. Note d'lchtyologie ouest-Africaine. XV. - Surun requinrenard nouveau pour la faune d'Afrique Occidentale Frangaise Alopias superciliosus(Lowe) 1840? Bull Inst Fr Afr Noire. 1956;18:1257-1266.

19. Gruber SH, Compagno LJV. Taxonomic status and biology of the bigeye thresher, Alopias superciliosus. Fishery Bulletin. 1981;79(4):617-640.

20. Gubanov YP. The reproduction of some species of pelagic sharks from the equatorial zone of the Indian Ocean. Journal of Ichthyology. 1978;18:781-792.

21. Demski LS. Elasmobranch reproductive biology: implications for captive breeding. Journal of Aquariculture and Aquatic Science. 1990;5:9-12.

22. http://www.internalwaveatlas.com/Atlas_PDF/IWAtlas_Pg207_ AndamanSea.PDF. 27.

23. Hornby C, Kumar MA, Bhathal B, et al. Reconstruction of Andaman and Nicobar Islands (India) marine fish catch from 1950-2010. Fisheries Centre, University of British Columbia. 2015;1-26.

24. Jha DK, Devi MP, Vidyalakshmi R, et al. Water quality assessment using water quality index and geographical information system methods in the coastal waters of Andaman Sea, India. Mar Pollut Bull. 2015;100(1):555-561.

25. Vijayakumaran K, Varghese SP. India's national report to the Scientific Committee of the Indian Ocean Tuna Commission. Fishery Survey of India, Mumbai. 2012;pp.13. 
26. Branstetter S, JD McEachran. Age and growth of four carcharhinid sharks common to the Gulf of Mexico: a summary paper. In: T Uyeno, R Arai, T Taniuchi, K Matsuura (Eds.), Indo-Pacific fish biology: Proceedings of the Second International Conference on Indo Pacific. Tokyo: Ichthyology Society of Japan. 1986;pp.361-371.

27. Gubanov YP. On the biology of the thresher shark Alopias vulpinus(Bonnaterre) in the northwest Indian Ocean. $J$ Ichthyol. 1972;12:591-600.

28. Castro JI. Observations on the reproductive cycles of some viviparous North American sharks. Aqua: International Journal of Ichthyology. 2009;15(4):205-222.

29. Natanson LJ, Gervelis BJ. The reproductive biology of the common Thresher shark in the Western North Atlantic Ocean. Transactions of the American Fisheries Society. 2013;142:1546-1562.

30. Gilmore G.R. Observations on the embryos of the Longfin Mako, Isurus paucus, and the Bigeye Thresher Alopiassuperciliosus. Copeia. 1983;2:375-382.

31. Branstetter S. Early life-history implications of selected carcharhinoid and lamnoid sharks of the Northwest Atlantic. 17-28. In:Pratt HL, \&
Taninchi T et al. (Eds.), Elasmobranchs as Living Resources: Advances in the Biology, Ecology, Systematics, and the Status of the Fisheries, NOAA Tech Rep. 1990;90.

32. Nakamura H. On the two species of the thresher shark from Formosan waters. Mem Fac Sci Agric Taihoku Imp Univ. 1935;14:1-6.

33. Hixon MA. Term fetuses from a large common thresher shark, Alopias vulpinus. Calif Fish Game. 1979;65:191-192.

34. Castro JI. The sharks of North American waters. Texas A\&M University Press, College Station. 1983;pp.180.

35. Guitart-Manday D. Las pesquerias pelagico-oceanicas de corto radio de accion en la region noroccidental de Cuba. Oceanogr Inst, Acad of Sci Havana. Seria Oceanologica. . 1975;31:1-41.

36. Gubanov Ye P. The reproduction of some species of pelagic sharks from the equatorial zone of the Indian Ocean. J Ichthyol. 1979;18:781-792

37. Bhargava AK, Somvanshi VS, Varghese S. Pelagic sharks by catch in the tuna long line fishery of Indian Exclusive Economy Zone. In: Pillai NGK \& Menon NG, et al. (Eds.), Management of Scombroid Fisheries, CMFRI, Kochi. 2002;165-176. 